\title{
THE IMPACT OF ENERGY PRICES ON PRODUCT INNOVATION : EVIDENCE FROM THE UK REFRIGERATOR MARKET
}

François COHEN, Matthieu GLACHANT, Magnus SODERBERG 


\title{
The Impact of Energy Prices on Product Innovation: Evidence from the UK Refrigerator Market
}

\author{
François Cohen, Centre for International Environmental Studies, Graduate \\ Institute of International and Development Studies, Geneva, Switzerland \\ Matthieu Glachant*, MINES ParisTech, PSL Research University, Paris, \\ France
}

Magnus Söderberg, University of Gothenburg, Sweden

\begin{abstract}
This paper uses product-level data from the UK refrigerator market to evaluate the impact of electricity prices on product innovation. Our best estimate is that a $10 \%$ increase in the electricity price reduces the average energy consumption of commercialized refrigerator models by $2 \%$. A large share of this reduction is explained by a reduction of freezing space. We also show that the exit of energy-inefficient products contributes more to energy reduction than the launch of new energy-efficient models. These findings suggest that innovation - the development of better technologies embodied in new products - does not respond strongly to energy price variations.
\end{abstract}

Keywords: Induced Innovation; Energy Efficiency; Electricity Prices; Multiple Imputations; Product entry and exit.

JEL Classification: D12, L68, Q41, Q55.

Acknowledgements: This research was funded by the Swiss National Science Foundation under the Sinergia programme, Project "Innovation, Diffusion and Green Growth" No CRSII1_147612. For useful comments, we would also like to thank Louis Gaëtan Giraudet, Sébastien Houde, Xavier Labandeira, three anonymous reviewers and workshop participants at La Toxa 2016. We are also grateful to GfK Retail and Technology for providing the data. 


\section{Introduction}

The influence of energy prices on green innovation has attracted a lot of attention in recent years. In particular, empirical studies, pioneered by Newell, Jaffe, \& Stavins (1999), have estimated the impact of energy price variations on the level of innovation in various sectors and technology fields: e.g. the auto industry (e.g. Aghion et al., 2016; Crabb \& Johnson, 2010), energy conservation (Popp, 2002; Noailly, 2012) and renewable energy (Diaz Arias \& van Beers, 2013).

Policy relevance is the primary reason for this interest. The production and use of energy strongly contribute to increasing greenhouse gas emissions. Meeting climate policy targets - in particular, the commitments formalized in the Paris Agreement to limit global warming below $2{ }^{\circ} \mathrm{C}$ above pre-industrial levels require drastic emission cuts that are only feasible with the development and diffusion of new energy technologies. Against this background, assessing the impact of energy prices on innovation is useful to predict how price-based policy instruments like emissions taxes and carbon markets can influence the pace of climate-friendly innovation. These investigations contribute to a broader literature on the relationships between green innovation and public regulation (for a survey, see Popp, Newell, \& Jaffe, 2010).

Previous papers have primarily relied on patent data for measuring the level of innovation. Patent data have advantages and weaknesses (for a discussion, see Griliches, 1990). On the positive side, they are easily available; they provide a wealth of information on both the nature of the invention and the applicant; they can be disaggregated into specific technological areas, a particularly useful characteristic when conducting sector- or technology-specific analyses. On the negative side, patents are a better measure of invention than they are of innovation. Schumpeter (1939) already makes the argument that many forms of innovation can occur without the production of any scientific novelty. On the other hand, the economic reception of an invention is uncertain. It follows 
that the future economic value of individual patents is heterogeneous: Many patents have very low value, and as a consequence the number of patents does not perfectly reflect the value of technological innovation. Furthermore, all inventions are not patented because some inventors may prefer secrecy to prevent public disclosure of the invention imposed by patent law, or to save the significant fees attached to patent filing; the propensity to patent differs across sectors and technologies.

This paper takes a different approach by looking at the result of innovation. Using product-level data from the UK refrigerator market, we examine the impact of electricity prices on the characteristics of the products actually sold on the market and we derive the impact on the energy consumption of sold appliances. In comparison with patent-based studies, the main advantage of the approach used in this paper is that it produces estimates of the impact of energy prices on the level of energy use induced by product innovation, which matters more for policy makers than the count of new patents. ${ }^{1}$ Doing so, we actually come closer to the strategy adopted by Newell, Jaffe, \& Stavins (1999) in their seminal study. However, their conceptual framework is different, which we clarify below. ${ }^{2}$

Looking at energy efficiency improvements in the white goods sector has strong policy relevance. Domestic appliances are responsible for a large share of the energy consumed by households: 16\% of energy consumed in the residential sector and more than $60 \%$ of residential electricity consumption in 2009 (Enerdata, 2010). At the same time, there is high potential for energy

\footnotetext{
${ }^{1}$ We restrict our analysis to product innovation. Other forms of innovation, such as process innovation (i.e. reductions in the cost of producing energy efficient appliances), are beyond the scope of this study.

${ }^{2}$ Newell, Jaffe, \& Stavins (1999) use data from the Sears catalogue and other publicly available information on 735 room air conditioners, 275 central air conditioners and 415 gas water heaters offered for sale between 1962 and 1993. They directly look at product attributes of commercialized products to assess the magnitude of induced innovation. Our method relies on a similar panel of appliances. Our method, explained in section 2, is however different from theirs.
} 
efficiency improvements; for example, an energy efficient refrigerator consume up to five times less energy than an energy inefficient one.

Methodologically, our approach starts from Lancaster (1966)'s view that, at any point of time, the refrigerator market includes many differentiated models, each being a particular combination of product characteristics (e.g. capacity, energy consumption, height, colour). Product innovation amounts to the launch of new models that substitute older ones. We then take advantage of the fact that we observe the dates of launch and exit of each model sold in the UK market between 2002 and 2007. We use a dynamic panel-data probit model (Wooldridge, 2005) to identify the impact of energy prices on the probability that a given model is commercialized.

This method faces two main econometric challenges. The first one results from the inclusion of refrigerator prices as a control variable in the product offer equation. This creates a simultaneity problem: A high price arguably increases the incentives to launch the product, but new products also modify the market equilibrium and thus the prices. We solve this issue by adopting a strategy inspired by Hausman et al. (1994), i.e. using the price of similar products as instrumental variables. ${ }^{3}$ The identification assumption is that prices in outside markets reflect underlying product cost and that stochastic market-specific factors are independent from those observed in the refrigerator market. The second challenge is that information on the price of refrigerator models that are not commercialized is not observed. We circumvent this problem by predicting prices for non-commercialized products by using multiple imputations. This gives unbiased standard errors when prices of noncommercialized products are used. ${ }^{4}$

\footnotetext{
${ }^{3}$ Hausman's approach is slightly different, but the logic is similar. He considers the price of the same product in different geographical markets.

${ }^{4}$ On the other side, refrigerators have some advantages compared to other energy-using products (e.g. cars, washing machines, dish washers) when studying how market outcomes are affected by energy prices. For example, refrigerators tend to be used with the same intensity at
} 
In the last stage of the analysis, using the econometric estimates, we produce a micro-simulation in order to calculate the impact of a $10 \%$ energy price increase on energy consumption of the models commercialized. We find that a $10 \%$ increase in the price of electricity reduces the energy consumption of commercialized products by $2 \%$. A large share of this reduction is explained by a reduction of freezing space. We also show that the exit of energyinefficient products contributes more to the reduction than the launch of new energy-efficient models. These findings suggest that innovative improvements in energy efficiency - the development of new energy-saving technologies embodied in new products - is not the primary response to energy price increases.

The remainder of the paper is structured as follows. Section 2 explains our modelling approach, detailing the challenges associated with the simultaneous price and commercialization decisions and unobserved prices of noncommercialized products. Section 3 describes the data. Section 4 presents the econometric results and we include the simulation of how product innovation is affected by an increase of the electricity price in Section 5. Section 6 concludes.

\section{Model}

To study product availability, we focus on the probability that a product is in the market. Thus, we jointly consider product entry and exit. ${ }^{5}$ Our dependent variable is $d_{j t}^{*}$ with $d_{j t}^{*}=1$ if the product $j$ is in the market in year $t$ and zero otherwise. As our base specification, we use the following probit model:

all times, i.e. energy consumption is fixed. This implies that intensity of use is hardly affected by the energy price.

${ }^{5}$ An alternative approach is to analyze product entry and exit separately with, for example, a survival model. This would drastically reduce the amount of information actually exploited and create censoring problems as we have a time dimension which is too short for survival models. 


$$
d_{j t}=\phi\left(\alpha d_{j t-1}^{*}+\beta p_{j t}+\gamma C_{j t}+\tau_{t}+\mu_{j}\right)
$$

where $\phi(\cdot)$ is a cumulative normal function with zero mean and a variance equal to one and $\alpha, \beta$ and $\gamma$ are parameters to be estimated. We adopt a dynamic specification with $d_{j t-1}^{*}$ as an independent variable in order to control for path dependence: launching a product is costly, which creates persistence. In the data, $44 \%$ of the products available at time $t-1$ are also available at time $t$, whereas only $21 \%$ of the products that are not available at $t-1$ can be found in the market at time $t$.

The main variable of interest is obviously the annual electricity cost $C_{j t}$. It is the product of model j's energy consumption (in $\mathrm{kWh}$ ) and the electricity price, which varies over time. An increase in $C_{j t}$ is expected to decrease the dependent variable $(\gamma<0)$ as it corresponds to a negative demand shock on the refrigerator market.

Our baseline econometric specification uses contemporaneous energy prices to compute running costs. Yet, the energy costs of an appliance will depend on the future electricity prices over the lifetime of the appliance. If expectations about future electricity prices are different from current prices (e.g. as suggested by Panzone, 2013), then we may not be employing the right metric to analyze the effect of energy prices on product entry and exit.

In fact, using contemporaneous energy prices is equivalent to assuming that consumers think that electricity prices follow a random walk. While there is support for this assumption (Ito, 2014), ${ }^{6}$ we can alternatively produce electricity price expectations based on the futures prices of the wholesale electricity market. The general idea behind using futures is that these constitute expectations about future prices from well-informed actors in the

\footnotetext{
${ }^{6}$ He finds that consumers are more responsive to average prices than to marginal electricity prices or to expected marginal electricity prices.
} 
electricity markets. This is done in Appendix D and results are very similar to our baseline specification.

We also include the refrigerator price $p_{j t}$, which is an obvious driver of product availability. However, its impact is difficult to predict. On the one hand, producers have incentives to keep products with high markups in the market, and thus high prices. On the other hand, an increase in the refrigerator price hurts demand, and thus reduces sales.

The equation includes time dummies and product fixed effects, $\tau_{t}$ and $\mu_{j}$ respectively. Product fixed effects are particularly important because refrigerators are differentiated goods, with several characteristics that are not observed in the data (e.g. product design, electronic readout) and that are likely to be correlated with energy performance (and thus $C_{j t}$ ). Fixed effects offer perfect controls as these attributes are product-specific and timeinvariant.

We estimate this dynamic probit model using the method suggested by Wooldridge (2005). The correlation between the product fixed effect $\mu_{j}$ and the initial value $d_{j, 0}^{*}$ is made explicit. We formulate that as:

$$
\mu_{j}=k_{0}+k_{1} d_{j 0}^{*}+k_{z} Z_{j}+\theta_{j}
$$

$Z_{j}$ is the row vector of all non-redundant explanatory variables in all time periods. It includes time-invariant product features (e.g., size or energy efficiency rating) but also the purchase price of products at each time period (i.e., the price in 2002, 2003..., 2007). To avoid multicollinearity, we exclude year dummies and only include the electricity cost for one year because they are calculated from the annual energy consumption of model $j$, which is a product feature that is given and does not vary over time. $k_{0}$ and $k_{1}$ are parameters, $k_{z}$ is a vector of parameters and $\theta_{j}$ is a random effect such that $\theta_{j} \mid\left(d_{j 0}^{*}, Z_{j}\right)$ follows a normal distribution. 
Substituting eq. (2) into eq. (1) leads to an estimable random-effects probit model with $d_{j 0}^{*}$ and $Z_{j}$ included as explanatory variables:

$$
d_{j t}=\phi\left(\alpha d_{j t-1}^{*}+\beta p_{j t}+\gamma C_{j t}+k_{0}+k_{1} d_{j 0}^{*}+k_{z} Z_{j}+\theta_{j}+\tau_{t}\right)
$$

The method by Wooldridge (2005) estimates a fixed effect dynamic probit model under the assumption that $\theta_{j}$ is normally distributed. To ensure that the results are robust to model choice, we also use a simpler fixed effect logit model with no dynamic component, which is displayed in Appendix A. Both the dynamic probit and the fixed effect logit model find statistically significant and negative impacts of energy costs on product commercialization.

\section{First-stage price equation}

The inclusion of the refrigerator price in eq.(3) poses two problems. The first is that the electricity cost $C_{j t}$ is likely to affect $p_{j t}$. Remember that an electricity price increase amounts to a negative demand shock on the refrigerator market and less demand leads producers to reduce their prices. Overall, the electricity cost potentially affects product availability both directly - as measured by coefficient $\gamma$ in eq.(3) - and indirectly through refrigerator price adjustments. A full evaluation of the impact of electricity prices thus requires us to estimate the price equation. Second, the product price could be endogenous because commercialization and prices are jointly determined in market equilibrium.

We use a control function approach to deal with the first two problems: we regress prices on a series of instruments and the electricity cost and then use predicted prices when estimating the probit model. Cost shifters are good candidates as instrumental variables. They obviously influence the refrigerator price as this price is the sum of the unit production cost and the markup. They are also exogenous: production cost shocks have no direct influence on the decision to launch or remove a product from the market when controlling for the refrigerator price as done in Eq. (3). We use the instruments developed by 
Cohen, Glachant and Soderberg (2017) and refer to Appendix B for a full description. In short, we exploit variations provided by the price of similar products in two outside markets: the upright freezer market (i.e. excluding chest freezers) and the washing machine market. Conceptually, we use the same strategy as Hausman et al. (1994). ${ }^{7}$ Freezer and washing machines are sold outside the refrigerator market, and thus to different consumers. This implies that taste shocks on these markets are less likely to be correlated with those experienced on the refrigerator market. This provides the basis for the exclusion requirement: the instruments will not be correlated with demand shocks on the refrigerator market. ${ }^{8}$ However, these products share similarities with refrigerators because they are also large domestic appliances. Cost shocks that affect the price of freezers and washing machines - e.g., an increase in steel price - are likely to be correlated across these markets. ${ }^{9}$

The difficulty with this approach is to match the prices of freezers or washing machines to the price of a specific refrigerator. Our solution is to use two product characteristics that are common to refrigerators, freezers, and washing machines, i.e. capacity and whether the appliance is built-in or freestanding. Using a hedonic pricing model, year-specific implicit prices for these two characteristics are estimated on product-level data for the UK freezer and

\footnotetext{
${ }^{7}$ Hausman et al. (1994) aim to identify cost-shifters when data on costs is missing. It uses information on the same products, but sold in different markets, to construct instruments. The idea is that demand shocks on different markets will not be correlated, whereas supply shocks are since we are talking about the same products, commercialized by multi-country firms. The idea behind our instrumentation strategy is similar: demand shocks on different product types should not be correlated, whereas these products are manufactured with similar material.

${ }^{8}$ There are a few elements that will substantially limit the correlation between demand shocks across these products. In particular, whereas everyone has a refrigerator at home, many households never buy a freezer and some households do not have a washing machine. Furthermore, these appliances have different lifetimes (washing machines have the shortest lifetime, freezer the longest lifetime) and the fact that an appliance breaks down largely explains the decision to buy a new appliance. Therefore, purchasing decisions are rarely performed at the same time.

${ }^{9}$ See the robustness checks in Cohen, Glachant and Soderberg (2017), which demonstrate that these instruments are strong predictors of the price of refrigerators.
} 
washing machine markets between 2002 and 2007, with data obtained from GfK. ${ }^{10}$ This technique yields year-specific averages for subcategories of freezers and washing machines, which are matched with the same subcategories of refrigerator-freezers and refrigerators. For example, the implicit price of smaller than average built-in freezers at time $t$ is used as an instrument for the price of smaller than average, built-in refrigerators and refrigerators-freezers at time $t .{ }^{11}$

In the end, we fit the following price equation:

$$
\ln \left(p_{j t}-n\right)=\delta C_{i t}+\rho_{1} w_{j t}+\rho_{2} f_{j t}+\theta_{j}+\tau_{t}+\eta_{j t}
$$

The dependent variable is a transformation of the product price with $n=$ 27.52 so that the predictions can be used to compute multiple imputations we provide detailed explanations below when presenting how we deal with missing price values. $w_{j t}$ is the implicit price in year $t$ of the washing machine of which size is similar to product $j . f_{j t}$ is the equivalent price for freezers. We also include product fixed effects $\theta_{j}$ and time dummies $\tau_{t} \cdot \eta_{j t}$ is the disturbance term.

\section{Missing information on product prices}

As mentioned previously, information on $p_{j t}$ is missing in the data for all periods when product $j$ is not available in the market $\left(d_{j t}^{*}=0\right)$. We therefore

\footnotetext{
${ }^{10}$ The hedonic approach is described in Appendix B. We run fixed effect regressions and interact specific product features with time dummies to capture shocks on the implicit price of these features. The regression therefore accounts for time-constant unobservables such as brands and stores in which the products are sold. Furthermore, the hedonic regression includes brand-specific time trends that control for the general development of brand-specific marketing strategies.

${ }^{11}$ The hedonic regressions include brand-specific time trends to control for brand-specific marketing strategies and image. Therefore, variations of the hedonic prices of the two characteristics do not capture changes in brand image, a feature that could be correlated with the sales of refrigerators with the same brand name. In addition, and to ensure that our estimation is not biased by changes in the retail sector, trade brand products have been withdrawn from the samples of freezers and washing machines used to estimate the implicit price of the two attributes.
} 
need to make an assumption about the purchase price of products in years when they are not available in the market. For all the products that are not commercialized at time $t$, one could perform a regression on observed refrigerator prices (when $d_{j t}^{*}=1$ ) and produce out-of-sample predictions for $p_{j t}$ when $d_{j t}^{*}=0$. However, this approach would underestimate the standard error of the estimated coefficients.

To solve this problem, we perform multiple imputations for each missing $p_{j t}$, a technique that provides unbiased standard errors for the estimated parameters (Rubin, 1987). The procedure is as follows. First, we look at the distribution of refrigerator prices $p_{j t}$ and perform a transformation on $p_{j t}$ so that the transformed refrigerator prices follow a distribution close to normal. ${ }^{12}$ The transformation that we use is:

$$
\tilde{p}_{j t}=\ln \left(\left[p_{j t}\right]-n\right)
$$

$\tilde{p}_{j t}$ are transformed prices, $n$ is a parameter that ensure that the skewness of the distribution is close to 0 , which is one property of normal distributions. In our case, we set $n=27.52$. $^{13}$ Then, we run a fixed effect linear regression on transformed prices:

$$
\tilde{p}_{j t}=h_{j}+\mathrm{a} C_{j t}+\mathrm{b} W_{j t}+\lambda_{t}+x_{j t}
$$

where $h_{j}$ is the product specific fixed effect, $\lambda_{t}$ the time fixed effect, $a$ is a parameter and $x_{j t}$ is the random error term. Importantly, $W_{j t}$ corresponds to the vector of instruments used to control for the commercialization-price endogeneity and $b$ is a vector of parameters. Using the instruments $W_{j t}$ in the imputation process allows us to control for the endogeneity on imputed

\footnotetext{
12 Such multiple imputation method is known to be biased if applied to non-normally distributed variables (Rubin, 1987).

${ }^{13}$ We have performed the Skewness and Kurtosis test on $\tilde{p}_{j, t}$. The p-values of this test is 0.99 with $n=27.52$. Thus, the normality hypothesis of $\tilde{p}_{j t}$ is not rejected.
} 
refrigerator prices. The predictions obtained from this regression are denoted $\hat{p}_{j t}$.

Based on the results of the linear regression, we create 25 imputed prices for each missing value of $p_{j t}$. Let $m$ denote the imputation number, then each imputed transformed price of product $j$ at time $t$ is given by:

$$
\tilde{p}_{j t}^{m}=\hat{p}_{j t}+x_{j t}^{m}
$$

where $x_{j t}^{m}$ is a randomly assigned and normally distributed error term corresponding to imputation $m$ for product $j$ at time $t$. Next, we use eq. (4) to calculate the value of the imputed prices $p_{j t}^{m}$ from their transformations $\tilde{p}_{j t}^{m}$. This step gives imputed values $p_{j t}^{m}$ with a distribution that is close to the distribution of observed prices. Once the $p_{j t}^{m}$ values have been obtained, we estimate eq. (3) as many times as there are imputations and then compute coefficient values and standard errors that account for the uncertainty of the value of $p_{j t}$ when $d_{j t}^{*}=0$.

The technique described above also solves the endogeneity problem of unobserved prices. In parallel and as previously explained, we also control for the endogeneity of observed refrigerator prices: we run a linear regression similar to eq. (5) and extract predicted values for observed prices that we use later in the dynamic probit model.

\section{Data}

We use product level data from 2002 to 2007 from the refrigerator market in the UK collected by the market research company GfK Retail and Technology (received by the Department for Environment, Food and Rural Affairs). The data includes detailed annual information on refrigerators and combined refrigerators-freezers sold in the UK. We identify products by brand name and 
series numbers. ${ }^{14}$ If not available, we rely on available information on product features (width, height, total capacity, energy consumption, energy efficiency rating, free-standing / built-in feature, availability of no-frost system and of freezer). ${ }^{15}$

Each observation is a product $j$ in year $t$ with information about the average consumer price and annual electricity consumption. Moreover, we observe the number of units sold and a set of product features such as size, whether it is a standard refrigerator or a combined refrigerator-freezer and indication of whether it has a separate freezing compartment that can store food at $-18^{\circ} \mathrm{C}$. We also know the product's classification according to the EU energy label. Energy labeling is mandatory since 1995 for all refrigerators sold in the European Union. In our data, each product is assigned to a class from $\mathrm{A}++$ (the most energy-efficient) to $G$ (the least energy efficient). This rating does not capture the absolute energy consumption of the appliance, but its relative consumption across different classes. ${ }^{16}$

We drop the following outliers: all products with less than 10 units of sales, and the $2.5 \%$ of products with the highest sales levels. ${ }^{17}$ We also drop the $2.5 \%$ products with the largest and smallest capacity and energy consumption. Any product falling within at least one of these categories is dropped from the sample.

\footnotetext{
${ }^{14}$ Note that a product that would be altered by manufacturers would be coded under a different series number, and would therefore have a different identifier in our dataset.

${ }^{15}$ Brand name and series numbers were not available for retailers' own brands. For these products, identification is based on product features alone. This means that, with this method, two models from different retailers' brand but with exactly the same product features cannot be properly distinguished. Therefore, observations for retailers' brand appliances are dropped each time the same product features corresponds to various models of appliances for the same year.

${ }^{16}$ However, the EU label also displays, next to the rating, the energy consumption of the appliance in $\mathrm{kWh}$ per year.

${ }^{17}$ The disappearance of best-selling products from one year to the other could only be due to dataset incompleteness.
} 
Summary statistics on product characteristics for the trimmed sample of observed, commercialized products are displayed in Table 1. It includes 4,928 observations consisting of the commercialization of product $j$ in year $t$. Table 2 provides an overview of the distribution of prices and market shares across energy efficiency classes. Note that almost all products were rated A, B or C during the study period. ${ }^{18}$

Electricity price statistics come from the UK Department of Energy and Climate Change (DECC, 2013). The UK experienced a surge in the electricity price by around 40\% between 2002 and 2007. The price reached about 12 pence per KWh by 2007. The increase in electricity prices was mostly due to a concomitant drastic increase in wholesale gas prices, which peaked in 2006. Gas is a major input in the UK electricity production market. Thus, electricity prices vary substantially over the 2002-2007 period.

\section{Results}

Table 3 gives the results of the dynamic probit model. They confirm that an increase in the electricity cost reduces the probability that the product is available on the market. Thus, highly energy-consuming products - energyinefficient products and large refrigerators - are more likely to exit the market when the electricity price increases. Likewise, a reduction in the selling price

\footnotetext{
${ }^{18}$ A potential problem is that the data does not include information on energy efficiency policies that may have influenced market outcomes. However, there has been no change in the design of the labeling scheme or in the strictness of the regulatory standards during the sample period. Admittedly, the Energy Efficiency Commitment (EEC) scheme was enforced during the study period, offering the possibility for eligible households to get financial support for the purchase of energy efficient cold appliances. However, this policy had very limited impact on the refrigerator market. In practice, support mostly focused on energy efficient light bulbs and on home insulation. Lees (2008) reports that subsidized fridge-freezers by EEC have represented $0.43 \%$ of the market between 2005 and 2008. If we also include subsidies from local authorities and the Warm Front, subsidized appliances may have represented around 1.5\% of all cold appliances sold between 2005 and 2008.
} 
of an appliance increases its probability of being kept in the market. This result is statistically significant at $1 \% .^{19}$

\section{Table 1: Summary statistics on product characteristics for} commercialized products

\begin{tabular}{l|c|c|c}
\hline \hline Variable & Unit & Mean & $\begin{array}{c}\text { Std } \\
\text { deviation }\end{array}$ \\
\hline Refrigerator price & real $£$ & 429.3 & 310.3 \\
\hline Energy consumption & kWh/year & 315.6 & 137.5 \\
\hline Annual energy cost & real $£$ /year & 31.6 & 14.1 \\
\hline Height & $\mathrm{cm}$ & 143.8 & 42.4 \\
\hline Width & $\mathrm{cm}$ & 60.2 & 10.3 \\
\hline Total capacity (cooling + freezing) & litres & 259.6 & 113.31 \\
\hline Freezing capacity & litres & 63.7 & 72.4 \\
\hline Energy efficiency rating & & 2.47 & 0.85 \\
\hline Share of combined refrigerators-freezers & & 0.55 & - \\
\hline Share of built-in appliances & & 0.76 & - \\
\hline Share of appliances with no-frost system & & 0.26 & - \\
\hline \hline
\end{tabular}

Notes. Source: GfK, provided by Defra. Survey years: 2002-2007. 4,928 observations. ${ }^{\mathrm{a}}$ To obtain a numeric value for the energy efficiency rating (from " $G$ " to " $A++$ "), ratings were recoded with " $\mathrm{A}++$ " set equal to 0 , "A+" $=1$, "A"=2 and so on up to " $\mathrm{G} "=8$.

Table 2: Price, number of products and average year of commercialization in the data, by energy efficiency class

\begin{tabular}{c|c|c|c|}
\hline \hline $\begin{array}{c}\text { Energy efficiency } \\
\text { rating }\end{array}$ & Average price & $\begin{array}{c}\text { Number of } \\
\text { observations }\end{array}$ & $\begin{array}{c}\text { Year of } \\
\text { commercialization }\end{array}$ \\
\hline A++ & 528.1 & 14 & 2006.3 \\
\hline A+ & 478.7 & 407 & 2006.2 \\
\hline A & 458.1 & 2886 & 2005.4 \\
\hline B & 400.7 & 1053 & 2004.3 \\
\hline C & 299.0 & 520 & 2003.4 \\
\hline D & 251.7 & 27 & 2002.6 \\
\hline E & 351.1 & 17 & 2003 \\
\hline F & 239.4 & 2 & 2003 \\
\hline G & 233.3 & 2 & 2004.5 \\
\hline
\end{tabular}

Notes. Source: GfK, made available by Defra. Survey years: 2002-2007. 4,928 observations.

${ }^{19}$ The probit model correctly predicts $62.5 \%$ of all observations, or more precisely $74.6 \%$ of all 0's (product is not commercialized) and 27.3\% of all 1's (product is commercialized). This is based on the assumption that products with a fitted probability over 0.5 are commercialized. 
The other parameters have the expected signs. For example, path dependence is confirmed: the probability that a product is available in year $t$ is higher if it was in the market in the year before. Conversely, a product available in 2002 is more likely to be obsolete in future years and therefore to exit the market (i.e. $k_{1}$ is negative).

\section{Table 3: Dynamic panel data probit estimation of product availability based on Wooldridge (2005)}

\begin{tabular}{l|c}
\hline Dependent variable & Availability of product $j: d_{j t}^{*}$ \\
\hline The product was commercialized the year before $(\alpha)$ & $0.6926^{* * *}$ \\
& $(26.42)$ \\
\hline Imputed refrigerator price $(\beta)$ & $-0.0016^{* * *}$ \\
Electricity costs $(\gamma)$ & $(6.01)$ \\
\hline The product was commercialized in $2002\left(k_{1}\right)$ & $-0.0489^{* * *}$ \\
& $(4.84)$ \\
\hline Non-redundant explanatory variables covering all time & $-0.3348^{* * *}$ \\
periods and including time-constant product features $\left(k_{z}\right)$ & $(11.34)$ \\
\hline Year dummies & Yes \\
\hline Observations & Yes \\
\hline Number of imputations for appliance prices & 15,875 \\
\hline \hline
\end{tabular}

Notes. $t$-statistics in brackets. Standard errors are robust to heteroskedasticity, clustered on products, and take into account uncertainty regarding the imputed values of appliance prices. Table 3 is estimated 25 times with different combinations of imputations for the product prices. The number of observations $(15,875)$ corresponds to the full sample of products used in the dynamic probit estimation $(3,175)$ times 5 years (from 2003 to 2007 since the 2002 data is used as the first lag). The number of observations is lower than the ones reported in the data table and used for the FE estimation for product prices. This is because we need observations to have non-missing information on all product features to be used in the panel data probit model. Results marked with $*, * *$ and $* * *$ are statistically significant at $10 \%, 5 \%$ and $1 \%$, respectively.

Table 4 displays the results of the first-stage price equation. Instruments are found to be strong. The joint F-test of significance has a statistic equal to 16.08. We find a statistically significant and negative coefficient for the electricity costs, suggesting that manufacturers buffer the increase in energy costs by reducing their product margins. For the average product in the sample, a $£ 1$ increase in energy costs translates into a $£ 7$ reduction in the refrigerator price. Considering that the lifetime of cold appliances is between 12 and 15 years, this means that only about half of the increase in energy costs 
translates into a reduction in the refrigerator price. This is consistent with economic literature, which says that consumers tend to underestimate the energy costs when they purchase domestic appliances (see Gillingham and Palmer, 2014, for a review on the energy efficiency gap).

Table 4: Fixed effect regression of the price of appliances

\begin{tabular}{l|c}
\hline Dependent variable & Ln(Price of product $j-27.52)$ \\
\hline Electricity costs & $-0.0178^{* *}$ \\
\hline Implicit price at time $t$ of a freestanding/build in & $(2.27)$ \\
washing machine of similar size & 0.0087 \\
\hline Implicit price at time $t$ of a freestanding/build in & $(1.64)$ \\
freezer of similar size & $0.0224^{* * *}$ \\
Product fixed effects & $(3.21)$ \\
\hline Year dummies & Yes \\
\hline Observations & Yes \\
\hline \hline
\end{tabular}

Notes. $t$-statistics in brackets. Standard errors are clustered on products. Results marked with *, ** and *** are statistically significant at $10 \%, 5 \%$ and $1 \%$, respectively.

\section{Simulation of a $10 \%$ electricity price increase}

This section assesses the impact of an electricity price increase on the characteristics of the products commercialized on the market. The main objective is to assess the extent to which total energy consumption decreases. Moreover, we also want to identify the channels through which this potentially occurs.

We chose to model a $10 \%$ increase in the price of electricity. This figure is an ad hoc value allowing the reader to easily compute elasticities to electricity prices. However, it also has some policy relevance. DECC (2014) estimates that the current cost of supporting home-grown, low-carbon sources of energy accounts for 5\% of a household energy bill. However, most of the electricity price fluctuations in the UK relate to fluctuations in wholesale gas prices.

We consider two scenarios: I) the Business-As-Usual (BAU) scenario as observed in the data; and II) a counterfactual scenario in which energy prices are $10 \%$ higher over the sample period. For each scenario, we compute the 
predicted probabilities that each product $j$ is available in year $t$. These probabilities are denoted $\hat{d}_{j t}^{I}$ and $\hat{d}_{j t}^{I I}$ respectively, where the superscript indicates the scenario number.

When calculating $\hat{d}_{j t}^{I}$ and $\hat{d}_{j t}^{I I}$, we take the dynamics of product entry and exit into account: a higher probability of exiting the market at time $t-1$ impacts the probability that the product is still available at time $t$. The relationship between $\hat{d}_{j t}^{a}$ and $\hat{d}_{j t-1}^{a} \forall a \in\{I ; I I\}$ is nonlinear and captured by the coefficient for the lagged dependent variable $(\alpha)$ in the dynamic probit model.

We restrict the calculation of $\hat{d}_{j t}^{a}$ to 2003-2007 to avoid making "out of sample" predictions on the probability that product $j$ is on the market at a later date. Furthermore, $\hat{d}_{j t}^{a}$ for 2002 cannot be calculated since it requires information on initial market conditions to make predictions from the dynamic probit model. We recurrently predict $\hat{d}_{j t}^{a}$ based on $\hat{d}_{j t-1}^{a}$ such that:

$$
\hat{d}_{j t}^{a}=\hat{d}_{j t-1}^{a} \Phi_{j t}\left(\alpha d_{j t-1}^{*} \mid d_{j t-1}^{*}=1\right)+\left(1-\hat{d}_{j t-1}^{a}\right) \Phi_{j t}\left(0 \mid d_{j t-1}^{*}=0\right)
$$

where $\Phi_{j t}\left(\alpha d_{j t-1}^{*}\right)$ is the probability that product $j$ is on the market at time $t$, depending on whether product $j$ was on the market at time $t-1$ or not. We use the functional forms of $\Phi_{j t}($.$) that have been estimated with the dynamic$ probit model. That is, $\Phi_{j t}=\phi\left(\hat{\alpha} d_{j t-1}^{*}+\hat{\beta} p_{j t}+\hat{\gamma} C_{j t}+\hat{k}_{0}+\hat{k}_{1} d_{j 0}^{*}+\hat{k}_{z} Z_{j}+\right.$ $\left.\hat{\theta}_{j}+\hat{\tau}_{t}\right)$ where $\hat{\alpha}, \hat{\beta}, \hat{\gamma}, \hat{k}_{0}, \hat{k}_{1}, \hat{k}_{\mathrm{Z}}, \hat{\theta}_{j}$, and $\hat{\tau}_{t}$ are coefficient estimates.

We also make recurrent predictions to calculate $\hat{d}_{j t}$ based on $\hat{d}_{j t-1}$. We therefore proceed as if we did not know the realized value of $d_{j t-1}^{*}$. This ensures that we model the effect of product entry and exit on market outcomes over more than one year.

Last, we account for the indirect impact of the electricity costs that passes through the refrigerator price with the first-stage price equation. We can therefore compute the impact of higher energy costs on the price of 
appliances, and from this the impact of lower refrigerator prices on the probability of commercialization. ${ }^{20}$

\section{Simulation results}

Table 5 presents the results of a first simulation where probabilities $\hat{d}_{j t}^{I}$ and $\hat{d}_{j t}^{I I}$ are used to compute weighted values for the average energy consumption under each scenario. We find that a $10 \%$ rise in electricity prices reduces average energy consumption by $2 \% .^{21}$

What is the composition of this reduction? As shown in Table 5, this energy reduction is partly due to a decrease in refrigerator capacity which decreases by $0.6 \%$. However, the major contribution is the $1.6 \%$ reduction of specific energy consumption, that is, energy consumption by liter of capacity. This could signal the inclusion of more efficient technologies in new models. However, the table shows that this mostly occurs through a decrease in freezing capacity (remember that freezing uses more energy than cooling).

As shown in the preceding section, electricity price shocks also affect refrigerator prices, and thereby energy consumption indirectly. Table 6 actually shows that the average refrigerator price decreases by $3.6 \%$ in response to the $10 \%$ electricity price increase. This figure is net of two phenomena. On the one hand, manufacturers modify the set of products available in the market. This new offer includes products of higher quality that sell at a $2.5 \%$ higher price under the BAU scenario. On the other hand, they

\footnotetext{
${ }^{20}$ In Appendix C, we account for both effects simultaneously. To do so, we run a dynamic probit model that does not control for the price of appliances. Therefore, the correlation between the price of appliances and electricity costs is captured by the electricity costs coefficient. Both methods display similar results: higher energy costs reduce the selling price of appliances and therefore soften the direct impact of energy costs on the likeliness that a product is commercialized.

${ }^{21}$ Note that this figure only considers the commercialization of the products. It does not consider the impact of electricity prices on the sales of commercialized models, which is analyzed in Cohen, Glachant and Soderberg (2017). Likewise, we are not computing the impact of the electricity price increase on the stock of appliances hold by UK households.
} 
reduce their margins. On average, the price of a given product is $6.1 \%$ lower under scenario II compared to the BAU scenario.

Table 5: Impact of the electricity price increase by $10 \%$ on average energy consumption, total capacity, freezing capacity, and energy labels of commercialized refrigerators (2003-2007)

\begin{tabular}{|l|c|c|c|}
\hline \hline Predicted average values & $\begin{array}{c}\text { Scenario I } \\
\text { Business as usual }\end{array}$ & $\begin{array}{c}\text { Scenario II } \\
\text { 10\% electricity price } \\
\text { increase }\end{array}$ & Variation \\
\hline $\begin{array}{l}\text { Energy consumption } \\
\text { (kWh/year) }\end{array}$ & 311.4 & 305.1 & $-2.0 \%$ \\
\hline $\begin{array}{l}\text { Total capacity (cooling + } \\
\text { freezing) } \\
\text { (litres) }\end{array}$ & 263.7 & 262.2 & $-0.6 \%$ \\
\hline $\begin{array}{l}\text { Specific energy consumption } \\
\text { (kWh/year/liters) }\end{array}$ & 1.18 & 61.5 & $-1.6 \%$ \\
\hline $\begin{array}{l}\text { Freezing capacity } \\
\text { (liters) }\end{array}$ & 63.8 & 2.25 & $-3.8 \%$ \\
\hline $\begin{array}{l}\text { Energy efficiency label } \\
\text { (scale 0 = A++, 8 = G) }\end{array}$ & 2.28 & $-1.2 \%$ \\
\hline \hline
\end{tabular}

Notes. The values for the business as usual scenario are predicted values. The values for the product actually commercialized are close to the averages predicted with the probit model. The average energy consumption is $315.6 \mathrm{kWh}$ per year (vs. $311.4 \mathrm{kWh}$ per year in the prediction) and the capacity is 259.7 litres (vs. 263.7 in the prediction).

Based on these results, we predict that energy consumption would decrease by $4 \%$ if the firms did not reduce refrigerator prices. Thus, seller price adjustments divide the energy savings by two.

Table 6: The average price of commercialized products under both scenarios

\begin{tabular}{|l|c|c|}
\hline \hline Price of commercialised products & Average & Variation \\
\hline Business as usual & $440.3 £$ & \\
\hline $\mathbf{1 0 \%}$ electricity price increase & $424.4 £$ & $-15.9 £$ \\
& & $(-3.6 \%)$ \\
\hline$\Delta$ due to a change in the composition of the product & & $+10.8 £$ \\
portfolio (assuming no change in individual product prices) & & $-2.5 \%)$ \\
\hline$\Delta$ Change in the refrigerator price of each product & & $(-6.1 \%)$ \\
\hline \hline
\end{tabular}

Last, we examine whether energy use variation is primarily due to the launch of new more energy-efficient models or to the exit of inefficient models. To do 
so, we focus the analysis on two subsets of products: entering products defined as models that were not available at time $t-1$ and that are commercialized at time $t$ in the BAU scenario. Exiting products are similarly defined as models commercialized at time $t-1$ that are no longer available at time $t$. Table 7 shows no differences in the impact of electricity price increases on product availability: The variation in the availability probabilities of the two sets of products is roughly similar, slightly more than $10 \%$. We however find that product exits tend to contribute more to energy savings. Again, these numbers suggest that the launch of new products embodying more efficient energy saving technologies is not the major determinant of the reduction in energy use since the disappearance of inefficient products contributes much to the change in the average energy consumption of commercialized appliances.

Table 7: Estimated availability probabilities and average energy consumption of entering and exiting products

\begin{tabular}{|l|c|c|c|}
\hline \hline & BAU & $\begin{array}{c}\mathbf{1 0} \% \text { electricity } \\
\text { price increase }\end{array}$ & Variation \\
\hline Predicted availability probability & & & $-11.8 \%$ \\
Entering products & 0.36 & 0.32 & $-13.2 \%$ \\
Exiting products & 0.32 & 0.28 & $-1.6 \%$ \\
Average energy consumption & 305.6 & 300.6 & $-2.3 \%$ \\
Entering products & 313.8 & 306.5 & \\
Exiting products & \multicolumn{2}{|l}{} \\
\hline
\end{tabular}

\section{Conclusions}

Recent economic research has found that policy can influence the pace of climate-friendly innovation. However, innovation empirical studies mostly use patent data and do not directly measure the impact of induced innovation on the environmental performance of products. Using detailed data on the UK refrigerator market, we look at the effect of increased electricity prices on the commercialization of energy-efficient products. 
We confirm that manufacturers adapt to higher energy prices by changing the portfolio of products that are available in the market. This change is not primarily driven by innovation of more energy efficient technologies, but by a reduction of freezing capacity. In addition, the exit of inefficient products contributes more than the launch of efficient products.

\section{References}

Aghion, P., Dechezleprêtre, A., Hémous, D., Martin, R. \& Van Reenen, J. (2016). Carbon Taxes, Path Dependency, and Directed Technical Change: Evidence from the Auto Industry. Journal of Political Economy, 124(1), 1-51.

Arias, A. D., \& van Beers, C. (2013). Energy subsidies, structure of electricity prices and technological change of energy use. Energy Economics, 40, 495502.

Cohen, F., Glachant, M., \& Soderberg, M. (2017). Consumer Myopia, Imperfect Competition and the Energy Efficiency Gap: Evidence from the UK Refrigerator Market. European Economic Review, 93, 1-23.

Crabb, J. M., \& Johnson, D. K. (2010). Fueling innovation: the impact of oil prices and CAFE standards on energy-efficient automotive technology. The Energy Journal, 199-216.

Department for Energy and Climate Change (DECC). (2014). Estimated Impacts of Energy and Climate Change Policies on Energy Prices and Bills.

Department of Energy and Climate Change (DECC). (2013). Domestic energy price statistics, including "Retail prices index: fuels components monthly figures" and "Average annual domestic standard electricity bills for selected towns and cities in the UK with average unit costs", last update May 2013, UK.

Enerdata. (2010). Energy Efficiency Trends for Households in the EU. Bruno Lapillonne, Carine Sebi, Karine Pollier in the framework of the ODYSSEE Project.

Gillingham, K. \& Palmer, K. (2014). Bridging the Energy Efficiency Gap: Policy Insights from Economic Theory and Empirical Analysis. Review of Environmental Economics \& Policy, 8(1), 18-38.

Griliches, Z. (1990). Patent statistics as economic indicators: a survey (No. w3301). National Bureau of Economic Research.

Hausman, J., Leonard, G., \& Zona, J. D. (1994). Competitive analysis with differenciated products. Annales d'Economie et de Statistique, 159-180.

Lancaster, K. J. (1966). A new approach to consumer theory. The journal of political economy, 132-157. 
Lees, E.W. (2008). Evaluation of the Energy Efficiency Commitment 2005-05. Report to DECC, Eoin Lees Energy.

Newell, R. G., Jaffe, A. B., \& Stavins, R. N. (1999). The Induced Innovation Hypothesis and Energy-Saving Technological Change. The Quarterly Journal of Economics, 114(3), 941-975.

Noailly, J. (2012). Improving the energy efficiency of buildings: The impact of environmental policy on technological innovation. Energy Economics, 34(3), 795-806.

Panzone, L. (2013). Saving money vs investing money: Do energy ratings influence consumer demand for energy efficient goods? Energy Economics, 38, 51-63.

Popp, D. (2002). Induced innovation and energy prices. The American Economic Review, 92(1), 160-180.

Popp, D., Newell, R. G., \& Jaffe, A. B. (2010). Energy, the environment, and technological change. Handbook of the Economics of Innovation, 2, 873-937.

Rubin, D.B. (1987). Multiple imputation for nonresponse in surveys. New York: Wiley

Schumpeter, J. (1939). Business Cycles. A Theoretical, Historical and Statistical Analysis of the Capitalist Process, McGraw-Hill Book Company.

Wooldridge, J. M. (2005). Simple solutions to the initial conditions problem in dynamic, nonlinear panel data models with unobserved heterogeneity. Journal of applied econometrics, 20(1), 39-54. 


\section{Appendix A: logit model of product commercialization}

As an alternative to Wooldridge's (2005) dynamic probit model, we run a fixed effect logit model to predict commercialization. Results suggest a negative impact of energy costs on product commercialization.

Table 8: Fixed effect logit model to estimate the impact of energy costs on product commercialization

\begin{tabular}{c|c}
\hline Independent variables & \\
\hline Imputed appliance price $(\beta)$ & $-0.0031^{* * *}$ \\
Electricity costs $(\gamma)$ & $-0.1114^{* * *}$ \\
& $(-7.42)$ \\
Year dummies & Yes \\
\hline Observations & 18,996 \\
\hline Number of imputations for appliance prices & 25 \\
\hline \hline
\end{tabular}

Notes. Standard errors take into account uncertainty regarding the imputed values of appliance prices. Results marked with *, ${ }^{* *}$ and ${ }^{* * *}$ are statistically significant at $10 \%, 5 \%$ and $1 \%$, respectively. 


\section{Appendix B: Construction of the instruments of the product offer equation}

To calculate the implicit price of the two attributes (capacity and built-in vs free-standing), a hedonic pricing model is used (see the results in Table 9). We run two regressions, one for freezers, and one for washing machines to capture the evolution of the price of each subcategory of refrigeration appliance. This is done by including year-'category of appliance’' (large/small and builtin/freestanding) specific fixed effects.

In addition, we include product-specific fixed effects that control for all timeinvariant product features and therefore for any difference in the sample of appliances that we observe from one year to the next, and could be susceptible to bias the estimation of the evolution of the average price of the various subcategories of appliances. As explained previously, we also include brandspecific time trends that control for the general development of brand-specific marketing strategies.

We assign weights to each product $j$ in our regressions. We do so to ensure that the regression results are representative of the market and to reduce the risk of measurement error on the average price of each model. The weights are identical for all of the observations of product $j$ between 2002 and 2007, and correspond to the average of all of the sales registered by product $j$ between 2002 and 2007. 
Table 9: Hedonic regressions to construct the instruments (freezers and washing machines)

\begin{tabular}{|c|c|c|c|}
\hline Dependent variable & $\begin{array}{c}\text { Price of washing } \\
\text { machines }\end{array}$ & $\begin{array}{l}\text { Price of built-in } \\
\text { freezers }\end{array}$ & $\begin{array}{c}\text { Price of } \\
\text { freestanding } \\
\text { freezers }\end{array}$ \\
\hline \multicolumn{4}{|l|}{$\begin{array}{l}\text { By year, by category of } \\
\text { appliance fixed effects }\end{array}$} \\
\hline Small, 2002 & 0 & 0 & $\begin{array}{c}-18.8481 \\
(-0.46)\end{array}$ \\
\hline Small, 2003 & $\begin{array}{l}-42.5061^{* * *} \\
(-3.11)\end{array}$ & $\begin{array}{c}-2.5749 \\
(-0.12)\end{array}$ & $\begin{array}{c}-18.4543 \\
(-0.42)\end{array}$ \\
\hline Small, 2004 & $\begin{array}{c}-75.2039 * * * \\
(-2.85)\end{array}$ & $\begin{array}{c}-11.508 \\
(-0.31)\end{array}$ & $\begin{array}{l}-5.8397 \\
(-0.11)\end{array}$ \\
\hline Small, 2005 & $\begin{array}{c}-125.6751^{* * *} \\
(-3.18)\end{array}$ & $\begin{array}{c}-16.0016 \\
(-0.29)\end{array}$ & $\begin{array}{l}-7.9437 \\
(-0.13)\end{array}$ \\
\hline Small, 2006 & $\begin{array}{c}-159.7466 * * * \\
(-3.05)\end{array}$ & $\begin{array}{c}-43.4277 \\
(-0.6)\end{array}$ & $\begin{array}{l}15.2585 \\
(0.2)\end{array}$ \\
\hline Small, 2007 & $\begin{array}{c}-205.2927 * * * \\
(-3.13)\end{array}$ & $\begin{array}{c}-38.6044 \\
(-0.45)\end{array}$ & $\begin{array}{c}19.0729 \\
(0.21)\end{array}$ \\
\hline Large, 2002 & $\begin{array}{c}37.824 \\
(1.45)\end{array}$ & $\begin{array}{c}10.3909 \\
(0.24)\end{array}$ & $\begin{array}{c}8.3791 \\
(0.28)\end{array}$ \\
\hline Large, 2003 & $\begin{array}{l}-3.9397 \\
(-0.12)\end{array}$ & $\begin{array}{c}1.2222 \\
(0.03)\end{array}$ & $\begin{array}{l}-2.8049 \\
(-0.08)\end{array}$ \\
\hline Large, 2004 & $\begin{array}{c}-57.4207 \\
(-1.59)\end{array}$ & $\begin{array}{l}13.543 \\
(0.31)\end{array}$ & $\begin{array}{c}9.7592 \\
(0.21)\end{array}$ \\
\hline Large, 2005 & $\begin{array}{l}-128.0074^{* * * *} \\
(-2.94)\end{array}$ & $\begin{array}{c}4.5595 \\
(0.08)\end{array}$ & $\begin{array}{l}17.6663 \\
(0.3)\end{array}$ \\
\hline Large, 2006 & $\begin{array}{c}-174.3192^{* * *} \\
(-3.18)\end{array}$ & $\begin{array}{c}12.0702 \\
(0.17)\end{array}$ & $\begin{array}{c}27.5309 \\
(0.38)\end{array}$ \\
\hline Large, 2007 & $\begin{array}{c}-218.5002^{* * *} \\
(-3.24)\end{array}$ & $\begin{array}{c}-14.9726 \\
(-0.18)\end{array}$ & $\begin{array}{c}29.2075 \\
(0.33)\end{array}$ \\
\hline Fixed effects & Yes & \multicolumn{2}{|c|}{ Yes } \\
\hline Brand-specific time trends & Yes & \multicolumn{2}{|c|}{ Yes } \\
\hline $\mathrm{R}^{2}$ & 0.31 & \multicolumn{2}{|c|}{0.28} \\
\hline Number of observations & 1,637 & \multicolumn{2}{|c|}{851} \\
\hline
\end{tabular}

Notes. $t$-statistics in brackets. Standard errors are robust to heteroskedasticity and clustered on products. Results marked with *, ** and *** are statistically significant at $10 \%, 5 \%$ and $1 \%$, respectively. 'Small' means below sample median, 'Large' is above. Regression is weighted for each observation of product $j$ by the total sales of product $j$ over 2002-2007. The prices for built-in and freestanding freezers have been obtained from the same regression, where this feature is interacted with size and year of commercialization. 


\section{Appendix C: Dynamic probit model without controlling for the refrigerator price}

Here we estimate base model, using the probit estimation, except that it does not control for the price of appliances at time $t$. Therefore, the coefficient of the electricity cost is net of the effect of electricity costs on the price of appliances. The estimated coefficient is around half the coefficient of the baseline specification. Simulation results (in table 11) are almost identical to the ones displayed in the main part of the paper. This corroborates the accuracy of our approach, which accounts for the impact of higher energy prices on appliance prices, and subsequently for the impact of lower appliance prices on product commercialization.

Table 10: Fixed effect regression of the refrigerator price

\begin{tabular}{l|c}
\hline Dependent variable & Availability of product $j: d_{j t}^{*}$ \\
\hline The product was commercialized the year before $(\alpha)$ & $0.7043^{* * *}$ \\
& $(27.10)$ \\
\hline Imputed appliance price $(\beta)$ & - \\
\hline Electricity costs $(\gamma)$ & $-0.0228^{* * *}$ \\
& $(3.07)$ \\
\hline The product was commercialized in $2002\left(k_{1}\right)$ & $-0.3342^{* * *}$ \\
$\begin{array}{l}\text { Non-redundant explanatory variables covering all } \\
\text { time periods and including time-constant product } \\
\text { features }\left(k_{z}\right)\end{array}$ & $(11.44)$ \\
\hline Year dummies & Yes \\
\hline Observations & Yes \\
\hline $\begin{array}{l}\text { Number of imputations for appliance prices: the } \\
\text { average of inputted values are included in }\left(k_{z}\right) .\end{array}$ & 15,875 \\
\hline \hline
\end{tabular}

Notes. $t$-statistics in brackets. Standard errors are robust to heteroskedasticity, clustered on products, and take into account uncertainty regarding the imputed values of appliance prices. Results marked with $*, * *$ and $* * *$ are statistically significant at $10 \%, 5 \%$ and $1 \%$, respectively. 
Table 11: Impact of a $10 \%$ electricity price increase on product offer

\begin{tabular}{|l|c|c|c|}
\hline \hline Predicted average values & Business as usual & $\begin{array}{c}\text { 10\% electricity } \\
\text { price increase }\end{array}$ & Impact \\
\hline $\begin{array}{l}\text { Energy consumption } \\
\text { (kWh/year) }\end{array}$ & 303.1 & 289.7 & $\begin{array}{c}-13.4 \\
(-4.4 \%)\end{array}$ \\
\hline $\begin{array}{l}\text { Total capacity (cooling } \\
\text { freezing) } \\
\text { (litres) }\end{array}$ & 259.7 & 260.1 & $\begin{array}{c}+0.4 \\
(+0.2 \%)\end{array}$ \\
\hline $\begin{array}{l}\text { Freezing capacity } \\
\text { (litres) }\end{array}$ & 63.7 & 52.9 & -10.8 \\
\hline $\begin{array}{l}\text { Energy efficiency label } \\
\text { (scale 0 = A++, 8 = G) }\end{array}$ & 2.31 & 2.17 & $-17.0 \%)$ \\
\hline \hline
\end{tabular}

Notes: relative impacts in brackets in fourth column. 


\section{Appendix D: Using expected electricity prices based on futures in the wholesale market and the probit model}

In the alternative specification below, we compute retail price expectations based on the futures prices from the wholesale electricity market. To do so, we reproduce the methodology described in Cohen, Glachant and Soderberg (2017). We use data on UK wholesale electricity futures from the Bloomberg futures database: the price of Gregorian baseload forwards from the 1st to the 4th following winter/summer seasons, as registered during OTC operations and gathered by GFI Group Limited. These prices are available on a monthly basis from 2002 to 2007. We also use data for spot prices of UK Power. The data was extracted from Bloomberg's reference and settlement data.

We report the results for the dynamic panel data probit model with the electricity price expectations below. Results are similar to the base model.

Table 12: Dynamic panel data probit estimation using expected prices, based on futures from the UK wholesale electricity market

\begin{tabular}{|c|c|}
\hline Dependent variable & Availability of product $j: d_{j t}^{*}$ \\
\hline The product was commercialized the year before $(\alpha)$ & $\begin{array}{c}0.6934 * * * \\
(26.45)\end{array}$ \\
\hline Imputed refrigerator price $(\beta)$ & $\begin{array}{l}-0.0015^{* * * *} \\
\quad(5.94)\end{array}$ \\
\hline Expected Electricity costs $(\gamma)$ & $\begin{array}{c}-0.0308^{* * *} \\
(4.52)\end{array}$ \\
\hline The product was commercialized in $2002\left(k_{1}\right)$ & $\begin{array}{c}-0.3348^{* * *} \\
(11.35)\end{array}$ \\
\hline $\begin{array}{l}\text { Non-redundant explanatory variables covering all time } \\
\text { periods and including time-constant product features }\left(k_{z}\right)\end{array}$ & Yes \\
\hline Year dummies & Yes \\
\hline Observations & 15,875 \\
\hline Number of imputations for appliance prices & 25 \\
\hline \multicolumn{2}{|c|}{$\begin{array}{l}\text { Notes. } t \text {-statistics in brackets. Standard errors are robust to heteroskedasticity, clustered o } \\
\text { products, and take into account uncertainty regarding the imputed values of appliance prices } \\
\text { Results marked with } *, * * \text { and } * * * \text { are statistically significant at } 10 \%, 5 \% \text { and } 1 \% \\
\text { respectively. }\end{array}$} \\
\hline
\end{tabular}

